\title{
Monocyte/HDL ratio predicts hypertensive complications
}

\author{
Kaplan $\mathrm{IG}^{1}$, Kaplan $\mathrm{M}^{2}$, Abacioglu $\mathrm{OO}^{2}$, Yavuz $\mathrm{F}^{2}$, Saler $\mathrm{T}^{1}$ \\ Adana City Hospital, Health and Science University, Internal Medicine Department, Adana, Turkey. \\ kardiomehmet27@hotmail.com
}

\begin{abstract}
OBJECTIVE: We aimed to investigate whether a simple and easily calculated parameter such as monocyte/ HDL ratio (MHR) may be used in predicting non-dipper (NDHT)-dipper HT (DHT) end organ damage. METHODS: 70 NDHT and 73 DHT patient groups were included in the study according to ambulatory blood pressure screening results. Basic laboratory parameters and spot urine samples were evaluated. Transthoracic echocardiography and ophthalmological examination were performed for end-organ damages. RESULTS: The MHR among the groups was higher in the NDHT group; which was statistically significant $(p \leq 0.001)$. In the NDHT group, albumin, creatinine, protein values, protein/creatinine ratio in the spot urine were significantly higher than in the DHT group ( $p \leq 0.05)$. Left ventricular hypertrophy $(\mathrm{LVH})$ and retinopathy were also more frequently observed in the NDHT group ( $p \leq 0.001$ and $p=0.001$, respectively). MHR in patients with LVH and retinopathy was significantly higher than in those without these complications $(p=0.001)$.

CONCLUSION: Easy to use, non-invasive and simple calculation, MHR can be used to predict end organ damage in hypertensive cases, and can be also used to distinguish between DHT/NDHT groups. This data supports the role of inflammation (Tab. 7, Ref. 14). Text in PDF www.elis.sk. KEY WORDS: monocyte/HDL ratio, dipper, non-dipper, hypertensive complications.
\end{abstract}

\section{Introduction}

Hypertension (HT) can be defined as the blood pressure exceeding the normally accepted limits, or an increased risk of damage to target organs such as: heart, brain, kidney and retina. HT is a strong risk factor that increases the likelihood of various cardiovascular diseases (1). HT is responsible for $6 \%$ of adult deaths worldwide (2). The prevalence of hypertension increases with age in developed countries, affecting $25 \%$ of adults, and 70 $\%$ of individuals after the seventh decade (3). It has been demonstrated that there is no specific threshold blood pressure value in determining long-term cardiovascular risk, and cardiovascular risk increases as the blood pressure increases (4).

Recent studies showed that monocyte/HDL ratio (MHR) might be a new marker of inflammation and oxidative stress, and was also closely related to the presence and prognosis of some cardiovascular diseases (5). Therefore, the present study aimed to investigate whether a simple and easily calculated parameter such as: monocyte / HDL ratio can be used to predict non-dipper-dipper HT end organ damage.

\footnotetext{
${ }^{1}$ Adana City Hospital, Health and Science University, Internal Medicine Department, Adana, Turkey, and ${ }^{2}$ Adana City Hospital, Health and Science University, Cardiology Department, Adana, Turkey

Address for correspondence: M. Kaplan, MD, Adana City Hospital, Health and Science University, Cardiology Department, Adana, Turkey. Phone: +90.532 .4631285$
}

\section{Methods}

The study was approved by the Institutional Review Board. Informed consent was obtained from all the participants. All procedures followed the ethical standards of the responsible committee on human experimentation and the Helsinki Declaration. Power analysis $(80 \%)$ was performed to determine the optimal sample size for the study.

Patients, who applied to the Internal Medicine Outpatient Clinic of Adana City Training \& Research Hospital, between January 1st and December 31st 2018, with the complaint of high blood pressure, and received the diagnosis of non-dipper and dipper HT based on ambulatory blood pressure results, were included. Two groups were planned in the study. Group 1 is, according to ambulatory blood pressure analysis, patients with $\mathrm{a} \geq 10 \%$ drop in blood pressure at night and diagnosed as dipper HT -73 patients. Group 2 is, according to ambulatory blood pressure analysis, patients diagnosed as non-dipper HT with a $<10 \%$ drop in blood pressure at night -70 patients.

The age, sex, comorbid diseases and demographic characteristics of 143 patients included in our study were recorded in detail. Routine biochemical tests were requested from the patients. Patients were screened by the same cardiologist for the left ventricular hypertrophy in terms of complications. Fundus examination was performed by a single specialist for a possible hypertensive retinopathy in the ophthalmology clinic. In addition to routine blood tests, spot protein, creatinine and albumin in the urine were examined for possible hypertensive nephropathy. 
$133-136$

\section{Exclusion criteria}

- Presence of known cardiac history

- Renal dysfunction (Creatinine $>3 \mathrm{mg} / \mathrm{dl}$ )

- Chronic liver diseases, rheumatologic, hematological diseases

- Malignancies

- Presence of active infection

- Diabetes mellitus

- Known drug usage or history of chronic disease requiring transfusion.

\section{Statistical analysis}

All statistical tests were carried out using SPSS 22.0 for Windows (SPSS Inc., Chicago, Illinois, USA). Continuous data are expressed as the mean \pm standard deviation and categorical data are expressed as percentages. Kolmogorov-Smirnov test was used to test the distribution type. Normal distributed variables were compared with One Way ANOVA test and appropriate posthoc analysis. Non-normally distributed variables were compared with Kruskal-Wallis test. Mann Whitney U test was used for the post-hoc analysis. The $\mathrm{x}^{2}$-test was used to assess differences in categorical variables between groups. The relationship between quantitative variables was tested with the Spearman rank correlation coefficient. The results are expressed as the relative risk and $95 \%$ confidence interval (CI). A p less than 0.05 was considered statistically significant.

\section{Results}

The mean age of the patients in the Group 1(DHT) was 52.06 \pm 11.8 and the mean age of the patients in the Group 2 (NDHT) was $53.10 \pm 8.86$. Body mass indexes were similar; the mean body mass index (BMI) of Group 1 was $29.3 \pm 4.19$ and the mean BMI of Group 2 was $28.3 \pm 3.4$. There were 36 male patients and 37

Tab. 1. The demographic properties of groups, mean blood pressure and laboratory parameters.

\begin{tabular}{|c|c|c|c|}
\hline & $\begin{array}{c}\text { Dipper HT } \\
\mathrm{n}=73(\text { Group } 1)\end{array}$ & $\begin{array}{l}\text { Non-dipper HT } \\
\mathrm{n}=70 \text { (Group 2) }\end{array}$ & $\mathrm{p}$ \\
\hline Age (years) & $52.07 \pm 11.83$ & $53.10 \pm 8.86$ & 0.557 \\
\hline BMI & $29.32 \pm 4.19$ & $28.32 \pm 3.40$ & 0.120 \\
\hline $\begin{array}{l}\text { Systolic blood pressure } \\
\text { (mean) } \mathrm{mmHg}\end{array}$ & $144.17 \pm 5.83$ & $153.08 \pm 12.19$ & $\begin{array}{c}0.000 \\
\mathbf{p}<\mathbf{0 . 0 5} *\end{array}$ \\
\hline $\begin{array}{l}\text { Diastolic blood pressure } \\
\text { (mean) } \mathrm{mmHg}\end{array}$ & $91.56 \pm 8.31$ & $93.44 \pm 8.84$ & 0.192 \\
\hline Hemoglobin(g/dL) & $12.90 \pm 1.53$ & $13.40 \pm 1.77$ & 0.070 \\
\hline Monocyte $(/ \mu)$ & $0.54 \pm 0.49$ & $0.94 \pm 0.96$ & $\begin{array}{c}0.002 \\
\mathbf{p}<\mathbf{0 . 0 5} \%\end{array}$ \\
\hline Leukocyte $(/ \mu)$ & $7.78 \pm 1.64$ & $7.27 \pm 1.70$ & 0.072 \\
\hline Glucose mg/dL) & $89.13 \pm 9.63$ & $91.98 \pm 10.21$ & 0.088 \\
\hline Creatinine $(\mathrm{mg} / \mathrm{dL})$ & $0.68 \pm 0.18$ & $0.74 \pm 0.21$ & 0.089 \\
\hline $\mathrm{HDL}(\mathrm{mg} / \mathrm{dL})$ & $45.57 \pm 12.56$ & $35.11 \pm 10.29$ & $\begin{array}{c}0.000 \\
\mathbf{p}<\mathbf{0 . 0 5}\end{array}$ \\
\hline $\mathrm{LDL}(\mathrm{mg} / \mathrm{dL})$ & $142.45 \pm 46.47$ & $141.52 \pm 32.57$ & 0.891 \\
\hline Triglyceride $(\mathrm{mg} / \mathrm{dL})$ & $222.56 \pm 124.84$ & $212.86 \pm 102.82$ & 0.251 \\
\hline
\end{tabular}

female patients in Group 1. There were 35 male patients and 35 female patients in Group 2. There was no statistically significant difference between the groups in terms of age, sex and body mass index ( $p=0.55, p=0.93$ and $p=0.12$, respectively). The ambulatory blood pressure values of the patients in Group 1 and Group 2 are shown in Table 1 . The mean systolic blood pressure was significantly higher in Group 2 than in Group $1(\mathrm{p} \leq 0.001)$.

Monocyte levels were significantly lower in the patients in the Group 1 than the patients in the Group $2(p=0.03)$. HDL levels were significantly lower in the patients in Group 2 than the patients in Group 1 ( $\mathrm{p} \leq 0.001)$. There wasn't any statistically significant difference found between Group 1 and Group 2 in terms of other blood parameters shown in Table $1(\mathrm{p}>0.05)$.

The monocyte / HDL ratio (MHR) between the groups was higher in the NDHT group as shown in the Table 2 and it was sta-

Tab. 2. Spot urine parameters and Monocyte/HDL ratio between groups.

\begin{tabular}{|c|c|c|c|c|}
\hline Parameters & Groups & Mean & $\begin{array}{c}\text { Std. } \\
\text { deviation }\end{array}$ & $\mathrm{p}$ \\
\hline \multirow{2}{*}{$\begin{array}{l}\text { Spot urine albumin } \\
(\mathrm{mg} / \mathrm{dl})\end{array}$} & DHT (group 1) & 1.72 & 2.73 & \multirow{2}{*}{$0.001 *$} \\
\hline & NDHT (group 2) & 9.49 & 18.6 & \\
\hline \multirow{2}{*}{$\begin{array}{l}\text { Spot urine creatinine } \\
(\mathrm{mg} / \mathrm{dl})\end{array}$} & DHT (group 1) & 85.9 & 79.8 & \multirow{2}{*}{$<0.001 *$} \\
\hline & NDHT (group 2) & 146.8 & 97.6 & \\
\hline \multirow{2}{*}{$\begin{array}{l}\text { Spot urine protein } \\
(\mathrm{mg} / \mathrm{dl})\end{array}$} & DHT (group 1) & 8.09 & 9.9 & \multirow{2}{*}{$0.002 *$} \\
\hline & NDHT (group 2) & 36.9 & 74.7 & \\
\hline \multirow{2}{*}{ Protein/creatinine ratio } & DHT (group 1) & 0.10 & 0.11 & \multirow{2}{*}{$0.033 *$} \\
\hline & NDHT (group 2) & 0.24 & 0.55 & \\
\hline \multirow{2}{*}{ Monocyte/HDL ratio } & DHT (group 1) & 0.013 & 0.015 & \multirow{2}{*}{$<0.001 *$} \\
\hline & NDHT (group 2) & 0.029 & 0.031 & \\
\hline
\end{tabular}

$* \mathrm{p}<0.05$ is significant

Tab. 3. End organ damages between groups.

\begin{tabular}{lcccc}
\hline Parameters & $\begin{array}{c}\text { NDHT } \\
\mathrm{n}=70 \text { (group 2) }\end{array}$ & $\begin{array}{c}\text { DHT } \\
\mathrm{n}=73 \text { (group1) }\end{array}$ & $\begin{array}{c}\text { TOTAL } \\
\mathrm{n}=143\end{array}$ & $\mathrm{p}$ \\
\hline Retinopathy (\%) & $31(44)$ & $14(23)$ & 45 & $=0.001^{*}$ \\
\hline LVH (\%) & $49(70)$ & $16(22)$ & 65 & $=<0.001^{*}$ \\
\hline$* \mathrm{p}<0.05$ is significant & & & &
\end{tabular}

Tab. 4. The relationship between MHR and end organ damages (LVH and Retinopathy) between groups.

\begin{tabular}{llcc}
\hline Parameters & & MHR (mean) & $\mathrm{p}$ \\
\hline \multirow{2}{*}{ LVH } & with $(\mathrm{n}=65)$ & $0.029 \pm 0.033$ & $0.001^{*}$ \\
& without $(\mathrm{n}=78)$ & $0.014 \pm 0.014$ & \\
\hline \multirow{2}{*}{ Retinopathy } & with $(\mathrm{n}=45)$ & $0.040 \pm 0.038$ & $<0.001^{*}$ \\
& without $(\mathrm{n}=98)$ & $0.012 \pm 0.007$ & \\
\hline \multirow{2}{*}{ * $<0.05$ is significant } & & &
\end{tabular}

Tab. 5. The stage of retinopathy.

\begin{tabular}{lcccc}
\hline & & \multicolumn{1}{c}{$\begin{array}{c}\text { DHT } \\
(\mathrm{n}=14)\end{array}$} & $\begin{array}{c}\text { NDHT } \\
(\mathrm{n}=31)\end{array}$ & Total \\
\hline \multirow{4}{*}{$\begin{array}{l}\text { Retinopathy } \\
(\mathrm{n}=45)\end{array}$} & Stage 1 & 6 & 10 & 16 \\
\cline { 2 - 5 } & Stage 2 & 7 & 10 & 17 \\
\cline { 2 - 5 } & Stage 3 & 1 & 8 & 9 \\
\cline { 2 - 5 } & Stage 4 & 0 & 3 & 3 \\
\hline
\end{tabular}


Tab. 6. MHR and stage of retinopathy.

\begin{tabular}{lccc}
\hline Retinopathy & Stage $\geq 2(\mathrm{n}=29)$ & Stage $1(\mathrm{n}=16)$ & $\mathrm{p}$ \\
\hline MHR & $0.050 \pm 0.045$ & $0.022 \pm 0.009$ & $0.021^{*}$ \\
\hline$* \mathrm{p}<0.05$ is significant & &
\end{tabular}

Tab. 7. Linear regression analysis of the study parameters patients with all three complications (retinopathy. nefropathy and LVH) of groups $(n=14)$.

\begin{tabular}{lccc}
\hline Parameters & $\begin{array}{c}\text { B-regression } \\
\text { value }\end{array}$ & $\begin{array}{c}\text { t- test statistical } \\
\text { value }\end{array}$ & $\mathrm{p}$ \\
\hline Age & -0.002 & -0.935 & 0.351 \\
\hline BMI & 0.010 & 1.657 & 0.100 \\
\hline Mean blood pressure & 0.007 & 2.743 & $\mathbf{0 . 0 0 7 *}$ \\
\hline Hemoglobin & 0.025 & 1.726 & 0.087 \\
\hline Glucose & -0.002 & -0.861 & 0.391 \\
\hline LDL & 0.000 & 0.778 & 0.438 \\
\hline Monocyte/HDL ratio & 2.163 & 2.057 & $\mathbf{0 . 0 4 2 *}$ \\
\hline
\end{tabular}

$* \mathrm{p}<0.05$ is significant, $* *$ Body mass index (BMI). High density lipoprotein (HDL), Low density lipoprotein(LDL)

tistically significant $(\mathrm{p} \leq 0.001)$. Spot urine albumin, creatinine, protein values and protein/creatinine ratio were significantly higher in the patients in Group 2 compared to the patients in Group 1, shown in the Table $2(\mathrm{p} \leq 0.05)$.

As shown in the Table 3, left ventricle hypertrophy (LVH) was found in $70 \%(n=49)$ of the patients diagnosed with NDHT, and retinopathy was found in $44.3 \%(n=31)$ of the patients diagnosed with NDHT. LVH was detected in $21.9 \%(n=16)$ of the patients diagnosed with DHT and retinopathy was detected in $19.2 \%(n=14)$ of the patients diagnosed with DHT. LVH and retinopathy were significantly higher in favor of Group 2, between Group 1 and Group 2, in terms of end organ damage ( $\mathrm{p} \leq 0.001$ and $\mathrm{p}=0.001$, respectively).

Among 65 patients with LVH and 78 patients without this complication; MHR was significantly higher in the group with LVH $(p=0.001)$. MHR was significantly higher in 45 patients diagnosed with retinopathy than in the group without retinopathy $(\mathrm{p}=0.001)$. This is summarized in the Table 4 .

Retinopathy was observed in 14 patients in the DHT group and in 31 patients in the NDHT group. The stages of retinopathy are shown in the Table 5. The mean MHR of patients with stage 1 and stage 2-3-4 retinopathy are shown in the Table 6 . There was a statistically significant difference in MHR between retinopathy stage 1 and other stages $(p=0.021)$.

There were positive correlations with the mean systolic blood pressure, the mean pulse pressure, fasting blood glucose and spot albumin; in the correlation analysis between MHR and study parameters $(\mathrm{p}<0.001,0.020,<0.001$; respectively). There wasn't any correlation with other values in the study. The results of the linear regression analysis of the study parameters, and all three complications are shown in the Table 7. The study included 143 patients, and there were 14 patients with all three complications of end organ damage; including nephropathy, retinopathy and LVH (13 patients in NDHT group and 1 patient in DHT group). When the study parameters were taken into the linear regression model, the MHR and the mean systolic blood pressure were found to be associated with all three complications $(p=0.042, p=0.007$; respectively).

\section{Discussion}

The incidence of hypertension (HT) increases by age. High blood pressure should be treated because it increases the risk of cardiovascular disease and mortality. HT is directly associated with left ventricular hypertrophy, heart failure, peripheral arterial disease, carotid atherosclerosis, and kidney disease (6-7). Dipping and non-dipping patterns are also important in hypertensive patients. End-organ damage is more common in the NDHT group, which does not show a decrease in blood pressure by more than $10 \%$ during sleep; and it is especially associated with left ventricular hypertrophy (LVH), congestive heart failure (CHF) and myocardial infarction, stroke and kidney damage (albuminuria and end renal failure) (8).

Yukihito et al conducted a study to evaluate the relationship between circadian rhythm and endothelial function in 18 patients diagnosed with essential HT. They found that in the NDHT group, endothelial-dependent vasodilation after intra-arterial acetylcholine infusion was more impaired than it was in the DHT group. In addition, they observed that nitric oxide production was lower in NDHT patients (9).

Ersoylu et al found that left ventricular diastolic dysfunction, LVH and arrhythmia frequency were higher in the NDHT group (10). In our study, LVH was more frequent in the NDHT group in accordance with literature. Among the groups with LVH $(n=65)$, and non-LVH ( $n=78)$, the MHR in the group with LVH was higher than it has been previously reported in literature, which is one of the important results of our study.

Proteinuria is an independent risk factor that may cause renal damage, although it is a symptom of the underlying disease. It was found that protein/creatinine $(\mathrm{P} / \mathrm{C})$ ratio pre-determined the decrease in renal function in patients with non-diabetic chronic kidney disease (11). The protein/creatinine ratio in spot urine given at any time of the day can be used as an easy and reliable method for measuring proteinuria. In our study, creatinine, albumin and protein were measured in spot urine. The protein/creatinine ratio in spot urine was $0.10 \pm 0.11$ in the DHT group and $0.24 \pm 0.55$ in the NDHT group. Proteinuria being higher in the NDHT group, as well as other complications, is consistent with literature.

One of the most important indicators of organ damage due to HT is retinopathy. Retinopathy caused by an uncontrolled hypertension is also an important parameter indicating the severity and prognosis of HT (12). Therefore, the examination of the retinal structure is important for the diagnosis and follow-up of HT. Duncan et al reported that low-grade hypertensive retinopathy might be also an indicator of morbidity and death due to cardiovascular diseases (12). In our study, hypertensive retinopathy was detected in 14 patients in the DHT group and in 31 patients in the NDHT group. Retinopathy being higher in the NDHT group, as well as other complications, is consistent with literature. The difference in MHR between the groups with stage 1 and stage $\geq 2$ retinopathy 
as a hypertensive complication has not been previously reported in literature, which is one of the important results of our study.

Comparing 45 patients with retinopathy and 98 patients without retinopathy in all patient groups, MHR was significantly higher in the retinopathy group $(\mathrm{p} \leq 0.001)$. According to the analysis, retinopathy stage increases as the MHR increases. The development of retinopathy is an inflammatory process, which has not been discussed in literature before and is one of the results that makes this study valuable.

In our study, 143 patients were included, and retinopathy, nephropathy and left ventricular hypertrophy were evaluated as a complication of HT. 13 of the 14 patients with all three complications were in the NDHT group. Complications were more common in the NDHT group, regarding all complications. It is clear that all these possible complications are the result of inflammatory processes. Recent studies showed that the MHR may be a new marker of inflammation and oxidative stress and coronary slow flow and $\mathrm{C}$ reactive protein (CRP) levels were found to be correlated with MHR.(5). The MHR is shown to be an independent predictor of increased cardiovascular events in patients with chronic renal failure, and to be associated with a poor prognosis for cardiovascular mortality (13). In addition to this, it was shown that MHR is closely related to stent thrombosis in patients, who underwent coronary stent implantation with primary percutaneous intervention (14).

In our study, MHR was significantly higher in the NDHT group $(p \leq 0.001)$. This parameter has not been examined in literature before. According to our findings, MHR was found to be higher in the group of patients with complications ( $\mathrm{LVH}$, proteinuria and retinopathy). MHR and the mean systolic blood pressure were found to be significant in the linear regression analysis performed in patients with all three complications. It is known in literature that complications of HT correlate with an increased mean systolic blood pressure.

HT complications seem to be predictable with a simple calculation of MHR. These data suggest that increased inflammation is a factor facilitating the development of HT complications. Our study showed that MHR, which is one of the indirect indicators of inflammation in hypertensive cases, may predict the complications of hypertension.

\section{Conclusion}

In the light of our data, monocyte/HDL ratio was found to be high in NDHT group. MHR was significantly higher in the groups with hypertensive end organ damage (left ventricular hypertrophy, retinopathy and proteinuria). MHR, which is an easy to use, non-invasive and simple calculation, can be used to predict end organ damage in hypertensive patients and can be used to differentiate between DHT/NDHT patient groups. There is not enough knowledge about this subject, and many questions are unanswered, therefore new studies are needed.

\section{References}

1. Kannel WB. Blood pressure as a cardiovascular risk factor: Prevention and treatment. J Amer Med Ass 1996; 275: 1571-1576.

2. Vasan RS, Larson MG, Leip EP, Evans JC, O'Donnell CJ, Kannel WB et al. Impact of high-normal blood pressure on the risk of cardiovascular disease. N Engl J Med 2001; 345: 1291-1297.

3. Thomas F, Bean K, Guize L, Quentzel S, Argyriadis P, Benetos A. Combined effects of systolic blood pressure and serum cholesterol on cardiovascular mortality in young ( 55 years) men and women. Eur Heart J 2002; 23: 528-535.

4. National High Blood Pressure Education Program working group report on primary prevention of hypertension. Arch Intern Med 1993: $153-186$.

5. Canpolat U, Cetin EH, Cetin S, Aydin S, Akboga MK, Yayla C et al. Association of monocyte-to-HDL cholesterol ratio with slow coronary Flow is Linked to Systemic Inflammation. Clin Appl Thromb Hemost 2016; 22: 476-482.

6. Kannel WB. Risk stratification in hypertension: New insights from the Framingham study. Am J Hypertens 2000; 13: 3-10.

7. Kuller LH, Shemanski L, Psaty BM, Borhani NO, Gardin J, Haan MN et al. Subclinical disease as an independent risk factor for cardiovascular disease. Circulation 1995; 92: 720.

8. Kurpesa M, Trzos E, Drozdz J, Bednarkiewicz Z, KrzeminskaPakula M. Myocardial ischemia and autonomic activity in dippers and non-dippers with coronary artery disease: assessment of normotensive and hypertensive patients. Int J Cardiol 2002; 83: 133-142.

9. Higashi Y, Nakagawa K, Kimura M et al. Circadian variation of blood pressure and endothelial function in patients with essential hypertension: a comparison of dippers and non-dippers. J Am Coll Cardiol 2002; 40: 2039-2043.

10. Ersoylu ZD, Tuğcu A, Yildirimtürk Ö, Aytekin V, Aytekin S. Comprasion of the incidences of left ventricular hypertrophy, left ventricular diastolic dysfunction, and arrhytmia between patients with dipper and nondipper hypertension. Arch Turk Soc Cardiol 2008; 36: 310-317.

11. Süleymanlar G. Böbrek Hastaliklarinin Tanisinda Kullanilan Laboratuar Testleri Erol Ç. İç Hastaliklari 1.baski, Ankara: Nobel Tip, 2008; $2713-2727$.

12. Duncan BB, Wong TY, Tyroler HA, Davis CE, Fuchs FD. Hypertensive retinopathy and incident coronary heart disease in high risk men. Br J Ophthalmol 2002; 86: 1002-1006.

13. Kanbay M, Solak Y, Unal HU, Kurt YG, Gok M, Cetinkaya H et al. Monocyte count/HDL cholesterol ratio and cardiovascular events in patients with chronic kidney disease. Int Urol Nephrol 2014; 46: 1619-1625.

14. Cetin EH, Cetin MS, Canpolat U, Aydin S, Topaloglu S, Aras D et al. Monocyte/HDL-cholesterol ratio predicts the definite stent thrombosis after primary percutaneous coronary intervention for ST-segment elevation myocardial infarction. Biomark Med 2015; 9: 967-977.

Received September 2, 2019. Accepted November 8, 2019. 